\title{
Electroanalytical characterization of the direct Marinobacter hydrocarbonoclasticus nitric oxide reductase-catalysed nitric oxide and dioxygen reduction
}

Filipa O. Gomes ${ }^{\mathrm{a}, \mathrm{b}}$, Luísa B. Maia ${ }^{\mathrm{b}}$, Cristina Cordas ${ }^{\mathrm{b}}$, Isabel Moura ${ }^{\mathrm{b}}$, Cristina DelerueMatos $^{a}$, José J. G. Moura ${ }^{b}$ and Simone Morais ${ }^{a^{*}}$

a REQUIMTE-LAQV, Instituto Superior de Engenharia do Instituto Politécnico do Porto, Rua Dr. António Bernardino de Almeida n 451, 4249-015 Porto, Portugal.

${ }^{\mathrm{b}}$ REQUIMTE-LAQV, Departamento de Química, Faculdade de Ciências e Tecnologia, Universidade Nova de Lisboa, Campus de Caparica, 2829-516 Caparica, Portugal.

*Corresponding author: email: sbm@isep.ipp.pt; Phone: +351 22834 0500; Fax: +351228321159.

\begin{abstract}
Understanding the direct electron transfer processes between redox proteins and electrode surface is fundamental to understand the proteins mechanistic properties and for development of novel biosensors. In this study, nitric oxide reductase (NOR) extracted from Marinobacter hydrocarbonoclasticus bacteria was adsorbed onto a pyrolytic graphite electrode (PGE) to develop an unmediated enzymatic biosensor (PGE/NOR)) for characterization of NOR direct electrochemical behaviour and NOR electroanalytical features towards $\mathrm{NO}$ and $\mathrm{O}_{2}$. Square-wave voltammetry showed the reduction potential of all the four NOR redox centers: $0.095 \pm 0.002,-0.108 \pm 0.008$, $0.328 \pm 0.001$ and $-0.635 \pm 0.004 \mathrm{~V}$ vs. SCE for heme $c$, heme $b$, heme $b_{3}$ and non-heme $\mathrm{Fe}_{\mathrm{B}}$, respectively. The determined sensitivity $\left(-4.00 \times 10^{-8} \pm 1.84 \times 10^{-9} \mathrm{~A} / \mu \mathrm{M}\right.$ and $-2.71 \times 10^{-}$ ${ }^{8} \pm 1.44 \times 10^{-9} \mathrm{~A} \mu \mathrm{M}$ for $\mathrm{NO}$ and $\mathrm{O}_{2}$, respectively), limit of detection $(0.5 \mu \mathrm{M}$ for $\mathrm{NO}$ and 1.0 $\mu \mathrm{M}$ for $\mathrm{O}_{2}$ ) and the Michaelis Menten constant (2.1 and $7.0 \mu \mathrm{M}$ for $\mathrm{NO}$ and $\mathrm{O}_{2}$, respectively) corroborated the higher affinity of NOR for its natural substrate (NO). No significant interference on sensitivity towards $\mathrm{NO}$ was perceived in the presence of $\mathrm{O}_{2}$, while the $\mathrm{O}_{2}$ reduction was markedly and negatively impacted (3.6 times lower sensitivity) by the presence of NO. These results clearly demonstrate the high potential of NOR for the design of innovative NO biosensors.
\end{abstract}

Keywords:

Direct electron transfer; Nitric oxide reductase; Heme proteins; Nitric oxide bioelectrocatalysis; Dioxygen bioelectrocatalysis. 


\section{Introduction}

Biological denitrification is an anaerobic pathway used by different bacteria to generate energy [1]. In denitrification, the reduction of nitrate to dinitrogen gas is accomplished by four different types of metalloenzymes (nitrate reductase, nitrite reductase, nitric oxide reductase (NOR) and nitrous oxide reductase) in four simple steps (nitrate $\rightarrow$ nitrite $\rightarrow$ nitric oxide $\rightarrow$ nitrous oxide $\rightarrow$ dinitrogen gas) [1]. In the third step, two nitric oxide radicals ( $\mathrm{NO}$, herein abbreviated $\mathrm{NO}$ ) are conjugated to form nitrous oxide and water in a two electron/proton reaction $\left(2 \mathrm{NO}+2 \mathrm{e}^{-}+2 \mathrm{H}^{+} \rightarrow \mathrm{N}_{2} \mathrm{O}+\mathrm{H}_{2} \mathrm{O}\right.$ (eq. 1)) with the involvement of NOR. NO is a signalling molecule involved in important biological processes in humans including neurotransmission, vasodilation, platelet aggregation, gene expression and apoptosis [2]. NO has also been implicated in a wide range of pathological processes, such as chronic infections and inflammations, diabetes, and neurological diseases (Parkinson and Alzheimer) [3]. Concerning NOR, three classes (cNOR, CuNOR and qNOR) exist, which are composed by different electron transfer centers and subunits [4]. cNOR, the first class, is a membrane enzyme with two different subunits, a NorB (the catalytic center) and a NorC (responsible for electron transfer) [5, 6]. cNOR can be extracted from Paracoccus denitrificans [7-9], Pseudomonas nautica (also designated as Marinobacter hydrocarbonoclasticus) [5, 10, 11], Pseudomonas aeruginosa [12, 13], Halomonas halodenitrificans [14], Roseobacter denitrificans [15] and Thermus thermophilus [16].

Several methods have been applied to study the NO reduction by different NORs, which included density functional theory (DFT) calculations [7, 12, 17], fluorescence [18], Raman $[19,20]$ and UV/Vis spectroscopy $[21,22]$. More recently, electrochemical methods, mainly cyclic voltammetry $[5,10,11]$ and spectroelectrochemistry [8] have been also explored due to their inherent advantages, namely inexpensive instrumentation, possibility of miniaturization, requirement of low volumes, high sensitivity and low limits of detection (LOD) [23-26]. Electrochemical biosensors, in particular third-generation biosensors (based on direct electron transfer (DET), i.e. in the absence of mediators, [27-31]) are the next promising step to detect $\mathrm{NO}$ in in vivo studies.

Recent works have permitted to obtain crucial information on NOR catalysis behaviour towards NO, however, some questions still remain unanswered due to controversial opinions $[5,10]$ One of those questions rely on the competition between the two most important substrates of this enzyme, $\mathrm{NO}$ and $\mathrm{O}_{2}$. Therefore, in this study, NOR purified from Marinobacter hydrocarbonoclasticus was adsorbed onto a pyrolytic graphite electrode (PGE) to produce an unmediated enzymatic biosensor (PGE/NOR) for characterization of NOR electroanalytical features towards $\mathrm{NO}$ and $\mathrm{O}_{2}$. In addition, the direct electrochemical behaviour of the purified NOR was evaluated.

\section{Materials and methods}

\subsection{Reagents}

n-dodecyl- $\beta$-D-maltoside (DM), di-potassium hydrogen phosphate $\left(\mathrm{K}_{2} \mathrm{HPO}_{4},>99 \%\right)$ and sulfuric acid $\left(\mathrm{H}_{2} \mathrm{SO}_{4}, 96 \%\right)$ were purchased from Panreac (Spain), 2-phenylethanol ( $\mathrm{PE}$, $\geq 99.0 \%$ ) from Sigma-Aldrich (Germany) and ethanol (>96\%) from Carlo Erba (Italy). Potassium hydroxide $(\mathrm{KOH}, 87.50 \%)$ and potassium dihydrogen phosphate $\left(\mathrm{KH}_{2} \mathrm{PO}_{4}\right.$, $99.50 \%$ ) were bought from Pronolab (Mexico) and Merck (USA), respectively. $\mathrm{NO}$ and $\mathrm{O}_{2}$ with the desired concentrations were prepared by dilution from buffer stock solutions. NO solutions of different concentrations were prepared by dilution from a buffer stock solution of $100 \mu \mathrm{M}$ prepared by bubbling a $5 \% \mathrm{NO} / 95 \%$ He gas mixture (Air Liquid, Portugal) into phosphate buffer $100 \mathrm{mM} \mathrm{pH} \mathrm{6.0.} \mathrm{For} \mathrm{the} \mathrm{O}_{2}$ effect study, the $\mathrm{O}_{2}$ concentration was varied by adding different volumes of air-equilibrated water (assumed 
as being $245 \mu \mathrm{M}$ at $25^{\circ} \mathrm{C}$ ) to the anaerobic reaction mixture. All solutions and stock were prepared immediately before being used. Ultrapure water obtained from a Millipore water purification system (18 M $\Omega$, Milli-Q; Millipore, Molsheim, France) was used in all experiments.

\subsection{NOR purification and characterization}

NOR is not commercially available and it was purified from membrane extracts of Marinobacter hydrocarbonoclasticus grown anaerobically as described by Prudêncio et al. [32]. The enzyme purity was estimated by its UV-visible spectrum ( $\mathrm{Abs}_{410} / \mathrm{Abs}_{280}$ ratio of 1.3; UV 1800-Shimadzu, Germany) [33] and electrophoresis assays under denaturation conditions (tricine SDS-PAGE) (Bio-Rad, Mini-PROTEAN® Tetra Handcast Systems, Portugal) based on the protocol of Laemmli [34]. Two bands corresponding to NOR subunits (NorC (17 kDa) and NorB (35-40 kDa)) were obtained and are in agreement with those presented by Girsch and de Vries [35]. Moreover, the specific activity of the purified NOR of $760 \mathrm{U} / \mathrm{mg}$ was determined by amperometry with an ISONO sensor (2 mm, World Precision Instruments, Inc., UK: one unit corresponds to 1 $\mu \mathrm{mol}$ of $\mathrm{NO} / \mathrm{min}$ ) as described previously by Timóteo et al. [33].

\subsection{Biosensor preparation}

PGE was sequentially hand polished with 5.0, 1.0 and $0.3 \mu \mathrm{m}$ alumina (Gravimeta Lda, Portugal), briefly sonicated with ethanol and finally rinsed with ultrapure water. Surface activation was performed by cyclic voltammetry (CV) in $0.5 \mathrm{M} \mathrm{H}_{2} \mathrm{SO}_{4}$ at $100 \mathrm{Vs}^{-1}$ in the range of 0 to $1.6 \mathrm{~V} v s$. saturated calomel electrode (SCE). NOR $(7 \mu \mathrm{L}$ of $14 \mathrm{mg} / \mathrm{mL}-$ $760 \mathrm{U} / \mathrm{mg}$ ) was then immobilized on the PGE surface $(0.4 \mathrm{~cm}$ diameter) using the solvent casting technique and dried using ultra-pure argon [36]. All the assays were conducted inside an anaerobic chamber (MBraun UniLab, Germany), at room temperature, where $\mathrm{O}_{2}$ concentration was set at $0.1 \mathrm{ppm}$.

\subsection{Electrochemical measurements}

The PGE/NOR was set as the working electrode, and a platinum wire and SCE were the secondary and reference electrodes, respectively. The three-electrode system was connected to an $\mu$ AUTOLAB potentiostat controlled by GPES 4.9.7 software (Eco Chimie). The redox behaviour of NOR was evaluated by $\mathrm{CV}$ at different scan rates (from 0.10 to $2.0 \mathrm{Vs}^{-1}$ ) in a potential range of 0.4 to $-0.9 \mathrm{~V}$ with a previous deoxygenation of the buffer solution (100 mM potassium phosphate buffer, $0.02 \%(\mathrm{v} / \mathrm{v}) \mathrm{DM}$ and $0.01 \% \mathrm{PE}$ at $\mathrm{pH}$ 6.0) using ultra-pure argon gas during 20 minutes. For the $\mathrm{O}_{2}$ effect study, the $\mathrm{O}_{2}$ concentration was varied by adding different volumes of air-equilibrated water (assumed as being $245 \mu \mathrm{M}$ at $25^{\circ} \mathrm{C}$ ) to the anaerobic reaction mixture. Bioelectrocatalytic studies of $\mathrm{NO}$ and $\mathrm{O}_{2}$ reduction were performed by $\mathrm{CV}$ at $5 \mathrm{mV} / \mathrm{s}$ and by square wave voltammetry (SWV) at $8 \mathrm{~Hz}$, step potential of $6 \mathrm{mV}$ and amplitude of $20 \mathrm{mV}$ in the same, as previously described, potential range.

\section{Results and discussion}

\subsection{Characterization of the nitric oxide reductase-based biosensor}

The characterization of the DET of the purified NOR was firstly performed by CV at 0.50 $\mathrm{Vs}^{-1}$ in buffer solution (100 $\mathrm{mM}$ potassium phosphate, $0.02 \% \mathrm{DM}$ and $0.01 \% \mathrm{PE}$ ) at $\mathrm{pH}$ 6.0 under anaerobic conditions (Fig. $1(\mathrm{~A})$ ). The $\mathrm{pH}$ of 6.0 was chosen based on the previous data reported by Duarte et al. [5] and Garny et al. [37] since, at this value, maximum enzyme catalytic activity was attained due to the protonation of the residues surrounding the catalytic centre. A cathodic (at $0.28 \mathrm{~V}$ ) and an anodic (at $0.26 \mathrm{~V}$ ) peak were detected with a formal potential $\left(\mathrm{E}^{0 \prime}\right)$ of $-0.27 \pm 0.01 \mathrm{~V}$ at $0.50 \mathrm{Vs}^{-1}$ corresponding to 
the low spin heme $b_{3}$ of the NOR bi-nuclear catalytic center, which is related to the reduction/oxidation of heme-(Fe(III)/Fe(II)) groups in accordance with Cordas et al. [10]. The observed cathodic $\left(\mathrm{I}_{\mathrm{pc}}\right)$ and anodic $\left(\mathrm{I}_{\mathrm{pa}}\right)$ peak current ratio $\left(\mathrm{I}_{\mathrm{pa}} / \mathrm{I}_{\mathrm{pc}}\right) \approx 1$ and the linear regressions of the $I_{p c}$ and $I_{p a}$ versus the tested scan rates $\left(\mathrm{V} ; 0.10\right.$ to $\left.2.0 \mathrm{Vs}^{-1}\right)$ ) (Fig. 1 (B)); $\mathrm{I}_{\mathrm{pc}}(\mathrm{A})=-2.56 \times 10^{-6} \pm 4.70 \times 10^{-8} \mathrm{v}\left(\mathrm{Vs}^{-1}\right)-1.32 \times 10^{-7} \pm 3.68 \times 10^{-8} ; \mathrm{r}^{2}=0.997 ; \mathrm{n}=10$ and $\left.\mathrm{I}_{\mathrm{pa}}(\mathrm{A})=2.60 \times 10^{-6} \pm 4.90 \times 10^{-8} \mathrm{v}\left(\mathrm{Vs}^{-1}\right)+7.17 \times 10^{-8} \pm 3.83 \times 10^{-8} ; \mathrm{r}^{2}=0.997 ; \mathrm{n}=10\right)$ indicated that this is a surface electron-transfer process with no diffusion control [38]. The peak to peak separation $(\Delta \mathrm{Ep})$ was $\approx 0 \mathrm{mV}$ for the highest scan rates $(0.35$ to $2.00 \mathrm{~V} / \mathrm{s})$, which is in agreement with the theoretical value for ideal surfaces, but $\Delta E p \approx 30 \mathrm{mV}$ for the lowest scan rates ( 0.1 to $0.23 \mathrm{~V} / \mathrm{s})$. This profile could be influenced by the amino acids around the heme $b_{3}$, the protonation states of ligands to the heme iron or the protonation of the water molecule coordinated to the iron center [39]. SWV assays allowed to observe the other NOR redox centers in addition to the redox signal of the previously described heme $b_{3}$-center (Fig. $1(\mathrm{C})$ ), due to the SWV higher sensitivity when compared with $C V$. The NOR reduction potential was determined for heme $c$, heme $b$, heme $b_{3}$ and non-heme $\mathrm{Fe}_{\mathrm{B}}$ as being $0.095 \pm 0.002,-0.108 \pm 0.008,-0.328 \pm 0.001$ and $-0.635 \pm 0.004 \mathrm{~V}$, respectively (Fig. 1 (C)) (at $50 \mathrm{~Hz}$, step potential of $5 \mathrm{mV}$ and amplitude of $20 \mathrm{mV}$ ). These results are in agreement with those previously reported for formal potentials of NOR (Table 1) with non-significant deviations, except for heme $c$ with a value of $0.033 \pm 0.017 \mathrm{~V}$ (this peak is less defined than the others, which may promote higher potentials discrepancies). Dependence between the peak current and the scan rate was perceived for all three redox centers that were not detected by CV (heme $c: I_{p}(A)=-$ $9.83 \times 10^{-7} \pm 1.62 \times 10^{-7} v\left(V^{-1}\right)-2.75 \times 10^{-8} \pm 3.64 \times 10^{-8} ; r^{2}=0.995 ; n=6$; heme $b: l_{p}(A)=-$ $1.04 \times 10^{-6} \pm 6.28 \times 10^{-8} v\left(\mathrm{Vs}^{-1}\right)+4.09 \times 10^{-8} \pm 2.33 \times 10^{-8} ; r^{2}=0.99 ; n=7 ;$ non-heme $F_{\mathrm{B}}: I_{\mathrm{p}}(\mathrm{A})$ $\left.=-2.05 \times 10^{-6} \pm 1.67 \times 10^{-7} \vee\left(\mathrm{Vs}^{-1}\right)-2.75 \times 10^{-7} \pm 4.66 \times 10^{-8} ; r^{2}=0.994 ; n=7\right)$ (Fig. 1 (D)).

\section{(Here Table 1)}

\section{(Here Figure 1)}

The surface concentration of the electroactive species and rate constant were also determined using the obtained electrochemical data. The surface concentration of the electroactive species $\left(\mathrm{T}^{*}\right.$, molcm$\left.^{-2}\right)$ was estimated based on equation 2 [40]:

$$
Q=n F A T^{*} \quad \text { Eq. } 2
$$

where $Q$ (A.s) is the charge involved in the reaction, $A\left(\mathrm{~cm}^{2}\right)$ is the geometric area of the working electrode, $\mathrm{n}$ is the number of the electron transferred, $\mathrm{F}\left(\mathrm{sA} \cdot \mathrm{mol}^{-1}\right)$ is the Faraday constant, as being $1.2 \times 10^{-11} \mathrm{molcm}^{-2}$, corresponding to a multilayer coating. By applying the Laviron model [41], a value of the rate constant, $\mathrm{k}_{\mathrm{s}}$, for the redox reaction of the catalytic heme $b_{3}$ centre was assessed as $0.60 \mathrm{~s}^{-1}$, demonstrating the good electron transfer between NOR and the electrode surface.

\subsection{Nitric oxide bioelectrocatalysis}

In this work, the NO bioelectrocatalysis by the PGE/NOR was followed by SWV and CV (Fig. 2). Heme proteins-modified electrodes using haemoglobin, myoglobin, cytochrome $c$, among others, have been applied for the detection of NO [42-44]. NOR, a specific bacterial heme protein, bioelectrocatalyses directly the $\mathrm{NO}$ to $\mathrm{N}_{2} \mathrm{O}$ reduction $(-0.71 \pm$ $0.01 \mathrm{~V}$; Fig. $2(\mathrm{~A}))$ with the release of water according to the reaction $2 \mathrm{NO}+2 \mathrm{e}^{-}$ 
$+2 \mathrm{H}^{+} \rightarrow \mathrm{N}_{2} \mathrm{O}+\mathrm{H}_{2} \mathrm{O}$ (eq. 3) [7], thus avoiding the necessity of using electroactive mediators. NOR catalytic subunit (NorB) is formed by a low-spin heme $b$ and a singular catalytic diiron center constituted by the heme $b_{3}$ and one non-heme iron $\left(\mathrm{Fe}_{\mathrm{B}}\right)$, which are bridged by a $\mu$-oxo/hydroxo group [45]. This special feature, when compared to the other proteins, seems to have a crucial role on the NOR higher specificity and efficiency for NO reduction, making it a very interesting target to develop new NO biosensors. Moreover, free energy profiles for NO reduction by NOR have been originating important information on its mechanism proving that it needs low activation energy to efficiently catalyze the NO reduction $[7,12,15]$. The irreversible behavior of NO reduction at the developed biosensor may be observed in Fig. 2 (B); Fig. 2 ((C)-(D)) exhibit the attained calibration curve data (square wave voltammograms and corresponding mean regression equation) when the $\mathrm{PGE} / \mathrm{NOR}$ was exposed to different concentration of dissolved NO $(0.50$ to $6.98 \mu \mathrm{M}): I_{p}(A)=-4.00 \times 10^{-8} \pm 1.84 \times 10^{-9}[N O](\mu \mathrm{M})-1.36 \times 10^{-7} \pm$ $6.78 \times 10^{-9} ; r^{2}=0.99 ; n=6$. These results were used to determine the detection (LOD; $3 \times$ the standard deviation of the $y$-intercept (Sy)/slope) and quantification (LOQ; 10xSyintercept/slope) limits [46], as being 0.5 and $1.7 \mu \mathrm{M}$, respectively. The Michaelis-Menten constant $\left(K_{m}\right)$ was also estimated according to the Michaelis-Menten equation (eq. 4).

$$
I_{s s}=I_{\max }[C] /\left(K_{m}+[C]\right) \quad \text { Eq. } 4
$$

where $I_{s s}(A)$ is the current after addition of the substrate; $C(\mu M)$ is the concentration of the substrate; $I_{\max }(A)$ is the maximum current measured under saturated substrate conditions [47]. The attained $K_{\mathrm{m}}$ value, $2.1 \mu \mathrm{M}$, is similar to $2.2 \mu \mathrm{M}$, which was reported by Duarte et al. [5] proving the great affinity of the purified NOR for the NO substrate (Table 1). This behaviour may be due to the efficient orientated immobilization of the catalytic center of NOR and its availability for NO reduction [5]. The determined catalytic rate constant $\left(\mathrm{k}_{\mathrm{cat}}\right), 1.82 \mathrm{~s}^{-1}$, is lower than the previously attained using steady-state kinetic experiments with NOR immobilised onto a graphite rotating disk electrode, mimicking the role of the physiological partner [5]. However, these comparisons should be made with caution since significantly different experimental setups and concentration ranges were used.

NOR was shown to be a divergent member of the superfamily of $\mathrm{O}_{2}$-reducing hemecopper oxidases [48]. This enzyme was also reported to be catalytically active towards $\mathrm{O}_{2}$ reduction trough the following reaction: $\mathrm{O}_{2}+4 \mathrm{H}^{+}+4 e^{-} \rightarrow 2 \mathrm{H}_{2} \mathrm{O}$ (Eq. 5) [17]. Therefore, the influence of $\mathrm{O}_{2}$ (at $\left.5.98 \mu \mathrm{M}\right)$ on the $\mathrm{NO}$ reduction was similarly characterized. No significant interference on sensitivity towards $\mathrm{NO}$ was perceived since the following data were achieved: $I_{p}(A)=-3.76 \times 10^{-8} \pm 1.95 \times 10^{-9}[\mathrm{NO}](\mu \mathrm{M})-9.87 \times 10^{-8} \pm 7.19 \times 10^{-9}$; $r^{2}=0.99$; $n=6$ ) (Fig. $2(E)-(F)$ ); the ratio between regression equation slopes (in the absence and presence of $\mathrm{O}_{2}$ ) was 1.06. These results also suggested that the reaction between $\mathrm{NO}$ and $\mathrm{O}_{2}$ to yield nitrogen dioxide radical, according to Eq. 6 under the low (physiological) NO concentrations [49, 50], did not significantly contribute to the consumption of NO.

$$
2^{\bullet} \mathrm{NO}+\mathrm{O}_{2} \rightleftharpoons 2{ }^{\bullet} \mathrm{NO}_{2} \quad \text { Eq. } 6
$$

Nevertheless, it should be noted that this reaction (Eq. 6) also interferes with the aerobic NO measurements by any (bio)sensor or methodology. Therefore, the attained biosensor sensitivity seems adequate to determine the NO release in biological systems or in environmental studies under anaerobic or aerobic conditions.

(Here Figure 2) 


\subsection{Dioxygen bioelectrocatalysis}

Using the same approach as the one applied for $\mathrm{NO}$, the $\mathrm{O}_{2}$ bioelectrocatalysis by NOR was studied by CV and SWV in the absence (Fig. 3 (A)-(D)) and in the presence (Fig. 3 $(E)-(F))$ of NO. The efficient $\mathrm{O}_{2}$ bioelectrocatalysis by NOR promoted the appearance of an irreversible reduction peak at $-0.25 \pm 0.02 \mathrm{~V}$ (Fig. $3(\mathrm{~A})-(\mathrm{C})$ ), which increased linearly with the $\mathrm{O}_{2}$ concentration from 1.22 to $11.67 \mu \mathrm{M}$. When NO was introduced at the 2.44 $\mu \mathrm{M}$ level, a significant negative impact on the biosensor sensitivity towards $\mathrm{O}_{2}$ was perceived with a value about 3.6 times lower $\left(I_{p}(A)=-7.57 \times 10^{-9} \pm 2.71 \times 10^{-10}\left[\mathrm{O}_{2}\right](\mu \mathrm{M})\right.$ $\left.8.06 \times 10^{-10} \pm 1.09 \times 10^{-9} ; r^{2}=0.994 ; n=6\right)$ than the reached in the absence of NO $\left(I_{p}(A)=-\right.$ $\left.2.71 \times 10^{-8} \pm 1.44 \times 10^{-9}\left[\mathrm{O}_{2}\right](\mu \mathrm{M})-3.93 \times 10^{-8} \pm 9.89 \times 10^{-9} ; r^{2}=0.99 ; n=6\right)$. On the other hand, the peak current of NO did not suffered any marked effect due to the augmentation of the $\mathrm{O}_{2}$ concentration in the electrolyte, being stable at $1.89 \times 10^{-7} \pm 9.00$ $\times 10^{-9} \mathrm{~A}(\mathrm{RSD}=4.8 \%$ at $2.44 \mu \mathrm{M} ; \mathrm{n}=6)$ (Fig. $\left.3(\mathrm{E})-(\mathrm{F})\right)$. As expected, the determined LOD $(1.0 \mu \mathrm{M})$ and LOQ $(3.2 \mu \mathrm{M})$ values for $\mathrm{O}_{2}$ electroanalysis were considerably higher than those reached for NO detection. Also, the greater Michaelis-Menten constant value (7.0 $\mu \mathrm{M})$, when compared to the $K_{\mathrm{m}}$ obtained for the bioelectrocatalysis of NO $(2.1 \mu \mathrm{M})$, reinforced the higher affinity of NOR to NO and the preference of this enzyme for its natural substrate.

(Here Figure 3)

\section{Conclusions}

A third generation biosensor composed by PGE/NOR was used to characterize the NOR electrochemical behaviour. Considering that NOR is catalytically active towards $\mathrm{NO}$ and $\mathrm{O}_{2}$ reduction, the bioelectrocatalysis of these two substrates, under anaerobic conditions, was studied when both existed separately and when the two substrates were in competitive environment. NOR demonstrated to have affinity for both substrates but exhibited a lower Michaelis Menten constant ( 2.1 for $\mathrm{NO} v s .7 .0 \mu \mathrm{M}$ for $\mathrm{O}_{2}$ ) for its natural substrate (NO). The attained high sensitivity for $\mathrm{NO}$ suggests the potential applicability of this NOR-based biosensor to real biological samples in aerobic conditions and demonstrate the possibility of using NOR in the design of unmediated nitric oxide biosensors. Still, further studies are needed to characterize other possible interfering substrates existing in real matrices. Moreover, future research is being undertaken to enhance the NOR electron transfer rate and lifetime at the PGE.

\section{Acknowledgments}

FG and LBM thank FCT/MCTES for the fellowship grants SFRH/BD/52502/2014 and SFRH/BPD/111404/2015, respectively, which are financed by national funds and cofinanced by FSE. CMC acknowledges FCT-MCTES funding through project PTDC/BBBBQB/0129/2014 (FCT/MCTES). This work was supported by the REQUIMTE, which is financed by national funds from FCT/MCTES (UID/QUI/50006/2013 and UID/Multi/04378/2013) and co-financed by the ERDF under the PT2020 Partnership Agreement (POCl-01-0145-FEDER-007265 and POCl-01-0145-FEDER-007728), and also by the PTDC/BB-BQB/0129/2014 project (FCT/MCTES). Funding through REQUIMTE project entitled "NOR-based biosensor for nitric oxide detection in biological and environmental samples" is also acknowledged. 


\section{References}

[1] P. Tavares, A.S. Pereira, J.J.G. Moura, I. Moura, Metalloenzymes of the denitrification pathway, J Inorg Biochem., 100 (2006) 2087-2100.

[2] S. Moncada, R.M. Palmer, E.A. Higgs, Nitric oxide: physiology, pathophysiology, and pharmacology, Pharmacol. Rev, 43 (1991) 109-142.

[3] F.X. Guix, I. Uribesalgo, M. Coma, F.J. Muñoz, The physiology and pathophysiology of nitric oxide in the brain, Prog. Neurobiol, 76 (2005) 126-152.

[4] W.G. Zumft, Nitric oxide reductases of prokaryotes with emphasis on the respiratory, heme-copper oxidase type, J Inorg Biochem., 99 (2005) 194-215.

[5] A.G. Duarte, C.M. Cordas, J.J.G. Moura, I. Moura, Steady-state kinetics with nitric oxide reductase (NOR): New considerations on substrate inhibition profile and catalytic mechanism, Biochim. Biophys. Acta, 1837 (2014) 375-384.

[6] Faye H. Thorndycroft, G. Butland, David J. Richardson, Nicholas J. Watmough, A new assay for nitric oxide reductase reveals two conserved glutamate residues form the entrance to a proton-conducting channel in the bacterial enzyme, Biochem. J, 401 (2007) 111-119.

[7] L.M. Blomberg, M.R.A. Blomberg, P.E.M. Siegbahn, Reduction of nitric oxide in bacterial nitric oxide reductase — a theoretical model study, Biochim. Biophys. Acta, 1757 (2006) 240-252.

[8] S.J. Field, M.D. Roldan, S.J. Marritt, J.N. Butt, D.J. Richardson, N.J. Watmough, Electron transfer to the active site of the bacterial nitric oxide reductase is controlled by ligand binding to heme $b_{3}$, Biochim. Biophys. Acta, 1807 (2011) 451-457.

[9] S.M. Kapetanaki, S.J. Field, R.J. Hughes, N.J. Watmough, U. Liebl, M.H. Vos, Ultrafast ligand binding dynamics in the active site of native bacterial nitric oxide reductase, Biochim. Biophys. Acta, 1777 (2008) 919-924.

[10] C.M. Cordas, A.G. Duarte, J.J.G. Moura, I. Moura, Electrochemical behaviour of bacterial nitric oxide reductase-Evidence of low redox potential non-heme $\mathrm{Fe}_{\mathrm{B}}$ gives new perspectives on the catalytic mechanism, Biochim. Biophys. Acta, 1827 (2013) 233238.

[11] C.M. Cordas, A.S. Pereira, C.E. Martins, C.G. Timóteo, I. Moura, J.J.G. Moura, P. Tavares, Nitric Oxide Reductase: Direct Electrochemistry and Electrocatalytic Activity, ChemBioChem, 7 (2006) 1878-1881.

[12] M.R. Blomberg, P.E. Siegbahn, Why is the reduction of NO in cytochrome $c$ dependent nitric oxide reductase (cNOR) not electrogenic?, Biochim. Biophys. Acta, 1827 (2013) 826-833.

[13] J.L. Robinson, J.M. Jaslove, A.M. Murawski, C.H. Fazen, M.P. Brynildsen, An integrated network analysis reveals that nitric oxide reductase prevents metabolic cycling of nitric oxide by Pseudomonas aeruginosa, Metab. Eng, 41 (2017) 67-81.

[14] T. Sakurai, S. Nakashima, K. Kataoka, D. Seo, N. Sakurai, Diverse NO reduction by Halomonas halodenitrificans nitric oxide reductase, Biochem Biophys Res Commun, 333 (2005) 483-487.

[15] A. Crow, Y. Matsuda, H. Arata, A. Oubrie, Structure of the membrane-intrinsic nitric oxide reductase from Roseobacter denitrificans, Biochemistry, 55 (2016) 3198-3203.

[16] L.A. Schurig-Briccio, P. Venkatakrishnan, J. Hemp, C. Bricio, J. Berenguer, R.B. Gennis, Characterization of the nitric oxide reductase from Thermus themophilus, Proc. Natl. Acad. Sci. U.S.A, 110 (2013) 12613-12618.

[17] M.R.A. Blomberg, P. Adelroth, The mechanism for oxygen reduction in cytochrome $c$ dependent nitric oxide reductase $(c \mathrm{NOR})$ as obtained from a combination of theoretical and experimental results, Biochim. Biophys. Acta, 1858 (2017) 884-894.

[18] S. Al-Attar, S. de Vries, An electrogenic nitric oxide reductase, FEBS Lett, 589 (2015) 2050-2057. 
[19] V. Daskalakis, T. Ohta, T. Kitagawa, C. Varotsis, Structure and properties of the catalytic site of nitric oxide reductase at ambient temperature, Biochim. Biophys. Acta, 1847 (2015) 1240-1244.

[20] E. Terasaka, N. Okada, N. Sato, Y. Sako, Y. Shiro, T. Tosha, Characterization of quinol-dependent nitric oxide reductase from Geobacillus stearothermophilus: enzymatic activity and active site structure, Biochim. Biophys. Acta, 1837 (2014) 1019-1026.

[21] L.Y. Chao, J. Rine, M.A. Marletta, Spectroscopic and kinetic studies of Nor1, a cytochrome P450 nitric oxide reductase from the fungal pathogen Histoplasma capsulatum, Arch. Biochem. Biophys, 480 (2008) 132-137.

[22] A. Daiber, H. Shoun, V. Ullrich, Nitric oxide reductase (P450nor) from Fusarium oxysporum, J. Inorg. Biochem, 99 (2005) 185-193.

[23] F. Wu, P. Yu, L. Mao, Bioelectrochemistry for in vivo analysis: Interface engineering toward implantable electrochemical biosensors, Curr. Opin. Electrochem, 5 (2017) 152157.

[24] T.M.B.F. Oliveira, M.F. Barroso, S. Morais, M. Araújo, C. Freire, P. de Lima-Neto, A.N. Correia, M.B.P.P. Oliveira, C. Delerue-Matos, Sensitive bi-enzymatic biosensor based on polyphenoloxidases-gold nanoparticles-chitosan hybrid film-graphene doped carbon paste electrode for carbamates detection, Bioelectrochemistry, 98 (2014) 20-29.

[25] T.M.B.F. Oliveira, M. Fátima Barroso, S. Morais, M. Araújo, C. Freire, P. de LimaNeto, A.N. Correia, M.B.P.P. Oliveira, C. Delerue-Matos, Laccase-Prussian blue filmgraphene doped carbon paste modified electrode for carbamate pesticides quantification, Biosens. Bioelectron, 47 (2013) 292-299.

[26] F.W.P. Ribeiro, M.F. Barroso, S. Morais, S. Viswanathan, P. de Lima-Neto, A.N. Correia, M.B.P.P. Oliveira, C. Delerue-Matos, Simple laccase-based biosensor for formetanate hydrochloride quantification in fruits, Bioelectrochemistry, 95 (2014) 7-14.

[27] $\mathrm{Y}$. Wu, S. Hu, Biosensors based on direct electron transfer in redox proteins, Microchim. Acta,, 159 (2007) 1-17.

[28] W. Zhang, G. Li, Third-generation biosensors based on the direct electron transfer of proteins, Anal Sci., 20 (2004) 603-609.

[29] X. Wu, F. Zhao, J.R. Varcoe, A.E. Thumser, C. Avignone-Rossa, R.C.T. Slade, Direct electron transfer of glucose oxidase immobilized in an ionic liquid reconstituted cellulose-carbon nanotube matrix, Bioelectrochemistry, 77 (2009) 64-68.

[30] T. Kuwahara, T. Asano, M. Kondo, M. Shimomura, Bioelectrocatalytic $\mathrm{O}_{2}$ reduction with a laccase-bearing poly(3-methylthiophene) film based on direct electron transfer from the polymer to laccase, Bioelectrochemistry, 91 (2013) 28-31.

[31] D. Nie, Y. Liang, T. Zhou, X. Li, G. Shi, L. Jin, Electrochemistry and electrocatalytic of hemoglobin immobilized on FDU-15-Pt mesoporous materials, Bioelectrochemistry, 79 (2010) 248-253.

[32] M. Prudencio, A.S. Pereira, P. Tavares, S. Besson, I. Cabrito, K. Brown, B. Samyn, B. Devreese, J. Van Beeumen, F. Rusnak, G. Fauque, J.J. Moura, M. Tegoni, C. Cambillau, I. Moura, Purification, characterization, and preliminary crystallographic study of copper-containing nitrous oxide reductase from Pseudomonas nautica 617, Biochemistry, 39 (2000) 3899-3907.

[33] C.G. Timóteo, A.S. Pereira, C.E. Martins, S.G. Naik, A.G. Duarte, J.J.G. Moura, P. Tavares, B.H. Huynh, I. Moura, Low-spin heme $b_{3}$ in the catalytic center of nitric oxide reductase from Pseudomonas nautica, Biochemistry, 50 (2011) 4251-4262.

[34] U.K. Laemmli, Cleavage of structural proteins during the assembly of the head of bacteriophage T4, Nature, 227 (1970) 680-685.

[35] P. Girsch, S. de Vries, Purification and initial kinetic and spectroscopic characterization of NO reductase from Paracoccus denitrificans, Biochim. Biophys. Acta, 1318 (1997) 202-216. 
[36] U. Siemann, Solvent cast technology - a versatile tool for thin film production, Scattering Methods and the Properties of Polymer Materials, Springer Berlin Heidelberg, Berlin, Heidelberg, 2005, pp. 1-14.

[37] S. Garny, N. Beeton-Kempen, I. Gerber, J. Verschoor, J. Jordaan, The coimmobilization of P450-type nitric oxide reductase and glucose dehydrogenase for the continuous reduction of nitric oxide via cofactor recycling, Enzyme Microb Technol, 85 (2016) 71-81.

[38] J.E. Frew, H.A. Hill, Direct and indirect electron transfer between electrodes and redox proteins, Eur J Biochem, 172 (1988) 261-269.

[39] F. Li, M. Nie, X. He, J. Fei, Y. Ding, B. Feng, Direct electrochemistry and electrocatalysis of hemoglobin on a glassy carbon electrode modified with poly(ethylene glycol diglycidyl ether) and gold nanoparticles on a quaternized cellulose support. A sensor for hydrogen peroxide and nitric oxide, Microchim. Acta, 181 (2014) 1541-1549.

[40] D. Grieshaber, R. MacKenzie, J. Vörös, E. Reimhult, Electrochemical biosensors Sensor principles and architectures, Sensors, 8 (2008) 1400.

[41] E. Laviron, General expression of the linear potential sweep voltammogram in the case of diffusionless electrochemical systems, J Electroanal Chem Interfacial Electrochem, 101 (1979) 19-28.

[42] H. Chen, G. Zhao, Nanocomposite of polymerized ionic liquid and graphene used as modifier for direct electrochemistry of cytochrome $c$ and nitric oxide biosensing, J Solid State Electrochem, 16 (2012) 3289-3297.

[43] C. Fan, J. Pang, P. Shen, G. Li, D. Zhu, Nitric oxide biosensors based on $\mathrm{Hb}$ /phosphatidylcholine films, Anal Sci., 18 (2002) 129-132.

[44] L. Zhang, G.-C. Zhao, X.-W. Wei, Z.-S. Yang, A nitric oxide biosensor based on myoglobin adsorbed on multi-walled carbon nanotubes, Electroanalysis, 17 (2005) 630634.

[45] J. Hendriks, A. Oubrie, J. Castresana, A. Urbani, S. Gemeinhardt, M. Saraste, Nitric oxide reductases in bacteria, Biochim. Biophys. Acta, 1459 (2000) 266-273.

[46] J. Mocak, A. Bond, S. Mitchell, G. Scollary, A statistical overview of standard (IUPAC and ACS) and new procedures for determining the limits of detection and quantification: application to voltammetric and stripping techniques (technical report), Pure Appl. Chem, 69 (1997) 297-328.

[47] J.E. Dowd, D.S. Riggs, A comparison of estimates of michaelis-menten kinetic constants from various linear transformations, J Biol Chem., 240 (1965) 863-869.

[48] J.A. Sigman, H.K. Kim, X. Zhao, J.R. Carey, Y. Lu, The role of copper and protons in heme-copper oxidases: kinetic study of an engineered heme-copper center in myoglobin, Proc. Natl. Acad. Sci. U.S.A, 100 (2003) 3629-3634.

[49] V.G. Kharitonov, A.R. Sundquist, V.S. Sharma, Kinetics of nitric oxide autoxidation in aqueous solution, J Biol Chem., 269 (1994) 5881-5883.

[50] L.B. Maia, J.J.G. Moura, How biology handles nitrite, Chem Rev, 114 (2014) 52735357. 


\section{Figure captions}

Figure 1. (A) Representative cyclic voltammograms of the electrochemical behavior of PGE (_ $)$ and PGE/NOR (----) in buffer solution at $0.50 \mathrm{Vs}^{-1}$. (B) Influence of the scan rate $\left(0.10,0.15,0.20,0.22,0.25,0.35,0.50,0.75,1.0\right.$ and $\left.2.0 \mathrm{Vs}^{-1}\right)$ on the oxidation $(\bullet)$ and reduction $(\bullet)$ peak current of the principal heme center of NOR (heme $b_{3}$ ). (C) Square-wave voltamograms of PGE/NOR biosensor at different frequencies $(20,30,40$, $45,50,70,100$ and $150 \mathrm{~Hz}$ ) (step potential of $5 \mathrm{mV}$ and amplitude of $20 \mathrm{mV}$ ) showing the non-heme $\mathrm{Fe}_{\mathrm{B}}(1)$, heme $b_{3}$ (2), heme $b$ (3) and heme $c$ (4) peak centers. (D) Influence of the scan rate $\left(0.10,0.15,0.20,0.22,0.25,0.35\right.$ and $\left.0.50 \mathrm{Vs}^{-1}\right)$ on the reduction peak current of non-heme $\mathrm{Fe}_{\mathrm{B}}(\star)$, heme $b(\bullet)$ and heme $c(\boldsymbol{\square})$ peak centers. Experimental conditions: Assays were performed under anaerobic conditions in $100 \mathrm{mM}$ potassium phosphate $\mathrm{pH} \quad 6.0,0.02 \%$ n-dodecyl- $\beta$-D-maltoside and $0.01 \%$ 2phenylethanol.

Figure 2. (A) Comparative square-wave voltammograms of the PGE ( - ) and PGE/NOR (----) exposed to $2.44 \mu \mathrm{M}$ NO. (B) Cyclic voltammograms of PGE/NOR biosensor exposed to two different NO concentrations (0.50 (_ ) and 2.44 (-----) $\mu \mathrm{M})$. (C) Square-wave voltamograms of NOR - catalysed NO reduction at $0.50,1.23,1.48$, $2.44,4.76,6.98 \mu \mathrm{M}$ and (D) the respective peak current vs. NO concentration curve. (E) Square-wave voltamograms of NOR - catalysed NO reduction at the same concentrations as indicated in (C)-(D) but in the presence of $5.98 \mu \mathrm{M}$ of $\mathrm{O}_{2}$; (F) respective peak current vs. NO concentration curve. Experimental conditions: Assays were performed under anaerobic conditions in $100 \mathrm{mM}$ potassium phosphate $\mathrm{pH}$ 6.0, $0.02 \% \mathrm{n}$-dodecyl- $\beta$-D-maltoside and $0.01 \% 2$-phenylethanol at $5 \mathrm{mV} / \mathrm{s}$ for $\mathrm{CV}$ and at frequency of $8 \mathrm{~Hz}$, step potential of $6 \mathrm{mV}$ and amplitude of $20 \mathrm{mV}$ for SWV.

Figure 3. (A) Comparative square-wave voltammograms of the PGE ( - ) and PGE/NOR (----) exposed to $5.98 \mu \mathrm{M} \mathrm{O}_{2}$. (B) Cyclic voltammograms of PGE/NOR biosensor exposed to two different $\mathrm{O}_{2}$ concentrations (1.22 (_) and 5.98 (----) $\left.\mu \mathrm{M}\right)$. (C) Square-wave voltamograms of NOR - catalysed $\mathrm{O}_{2}$ reduction at $1.22,3.02,3.62$, 5.98, $11.67 \mu \mathrm{M}$ and (D) the respective peak current vs. $\mathrm{O}_{2}$ concentration curve. (E) Cyclic voltamograms of NOR - catalysed $\mathrm{O}_{2}$ reduction at the same concentrations as indicated in (C)-(D) but in the presence of $2.44 \mu \mathrm{M}$ of $\mathrm{NO}$; (F) respective peak current vs. $\mathrm{O}_{2}$ concentration curve. Experimental conditions: Assays were performed under anaerobic conditions in $100 \mathrm{mM}$ potassium phosphate $\mathrm{pH} 6.0,0.02 \% \mathrm{n}$-dodecyl- $\beta$-Dmaltoside and $0.01 \%$ 2-phenylethanol at $5 \mathrm{mV} / \mathrm{s}$ for $\mathrm{CV}$ and at frequency of $8 \mathrm{~Hz}$, step potential of $6 \mathrm{mV}$ and amplitude of $20 \mathrm{mV}$ for SWV. 
Highlights

- Direct electron transfer of nitric oxide reductase (NOR) was described.

- NOR bioelectrocatalytic activity towards $\mathrm{NO}$ and $\mathrm{O}_{2}$ reduction was characterized.

- Lower Michaelis Menten constant was obtained for NO than for $\mathrm{O}_{2}$.

$-\mathrm{O}_{2}$ has no significant effect on NOR sensitivity towards NO reduction.

- The unmediated NOR-based biosensor can be useful for NO sensing in biological events. 
Table 1- Formal potential $\left(\mathrm{E}^{\mathrm{o}}\right)$ and Michaelis Menten constant $\left(K_{\mathrm{m}}\right)$ reported for nitric oxide reductase biosensors for NO detection.

\begin{tabular}{|c|c|c|c|}
\hline Biosensor & $E^{0}$ (V vs. SCE) & $\begin{array}{c}K_{\mathrm{m}} \\
(\mu \mathrm{M})\end{array}$ & Ref. \\
\hline NOR/Pyrolytic graphite electrode & $-0.368 \pm 0.013^{*}$ (heme $\left.b_{3}\right)$ & n.r. & [11] \\
\hline NOR/ Rotating graphite disk electrode & $\begin{array}{l}-0.610 \pm 0.014^{*}\left(\mathrm{Fe}_{\mathrm{B}}\right) \\
\left.-0.403 \pm 0.009^{*} \text { (heme } b_{3}\right) \\
\left.-0.198 \pm 0.012^{*} \text { (heme } b\right) \\
-0.033 \pm 0.017^{*} \text { (heme } c \text { ) }\end{array}$ & n.r. & [10] \\
\hline NOR/Rotating graphite disk electrode & Not reported & $\begin{array}{l}2.2 \text { for } \mathrm{NO} \\
\text { n.r. for } \mathrm{O}_{2}\end{array}$ & [5] \\
\hline NOR/Pyrolytic graphite electrode & $\begin{array}{l}-0.635 \pm 0.004\left(\mathrm{Fe}_{\mathrm{B}}\right) \\
-0.328 \pm 0.001\left(\text { heme } b_{3}\right) \\
-0.108 \pm 0.008 \text { (heme } b) \\
0.095 \pm 0.002(\text { heme } c)\end{array}$ & $\begin{array}{l}2.1 \text { for } \mathrm{NO} \\
7.0 \text { for } \mathrm{O}_{2}\end{array}$ & $\begin{array}{l}\text { This } \\
\text { study }\end{array}$ \\
\hline
\end{tabular}

* Potential values reported vs. NHE [10-11] were converted to potentials vs. SCE to allow comparison between studies. 


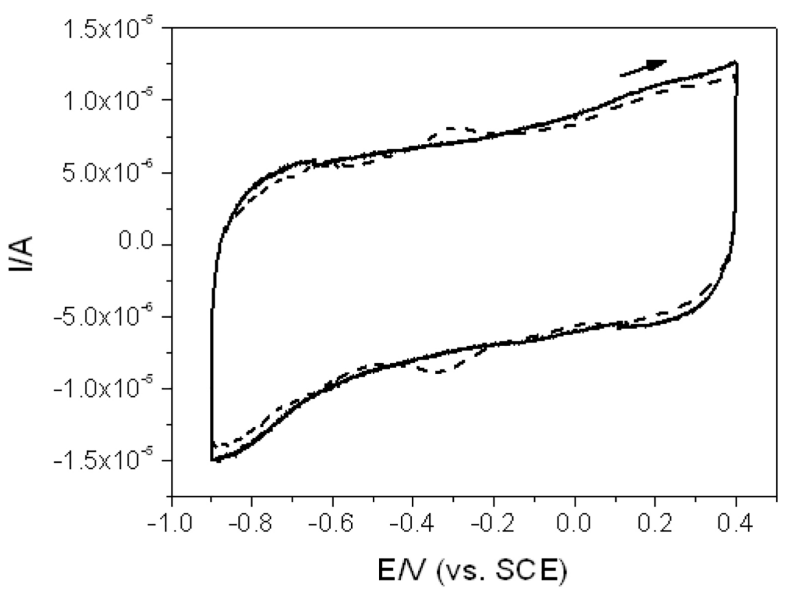

(A)

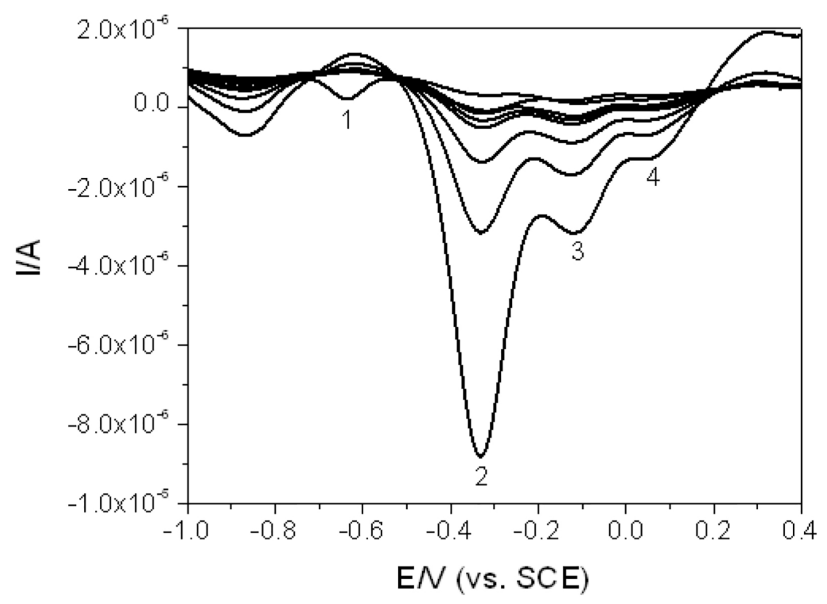

(C)

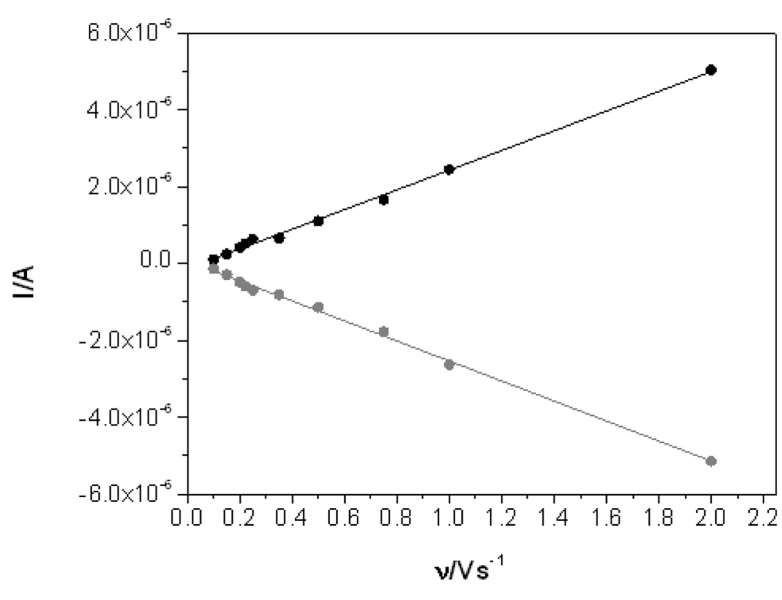

(B)

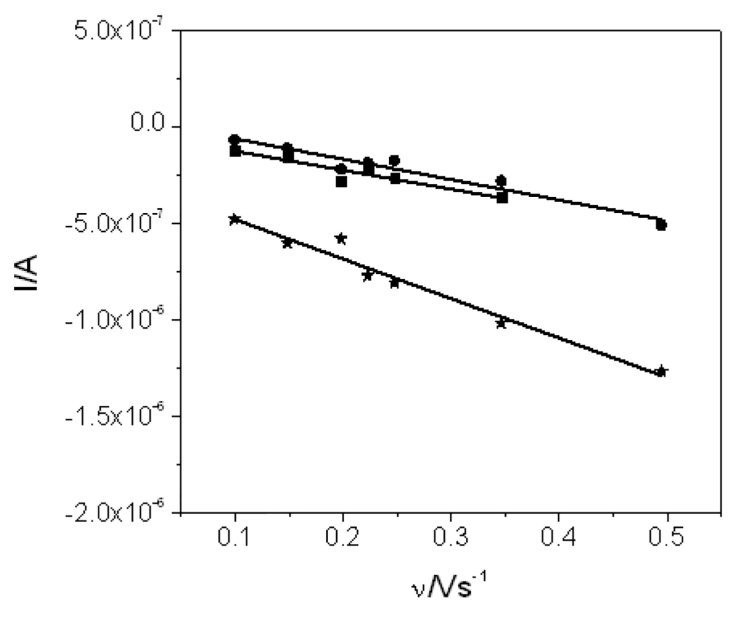

(D)

Figure 1 


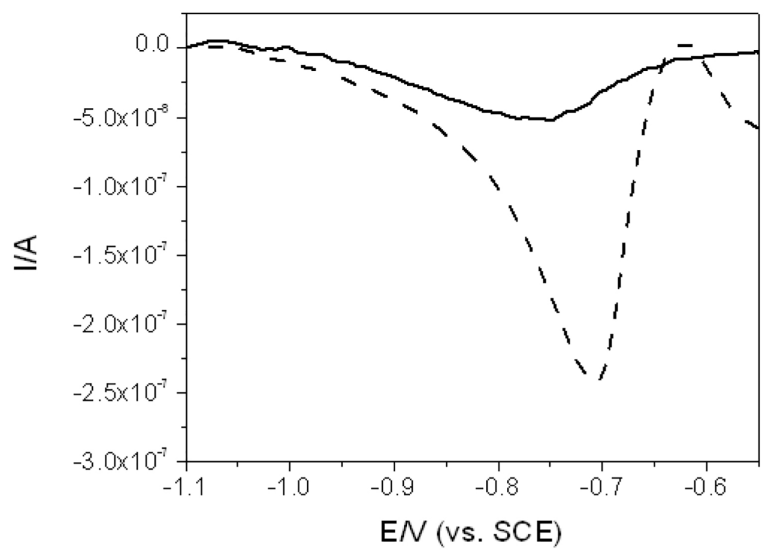

(A)

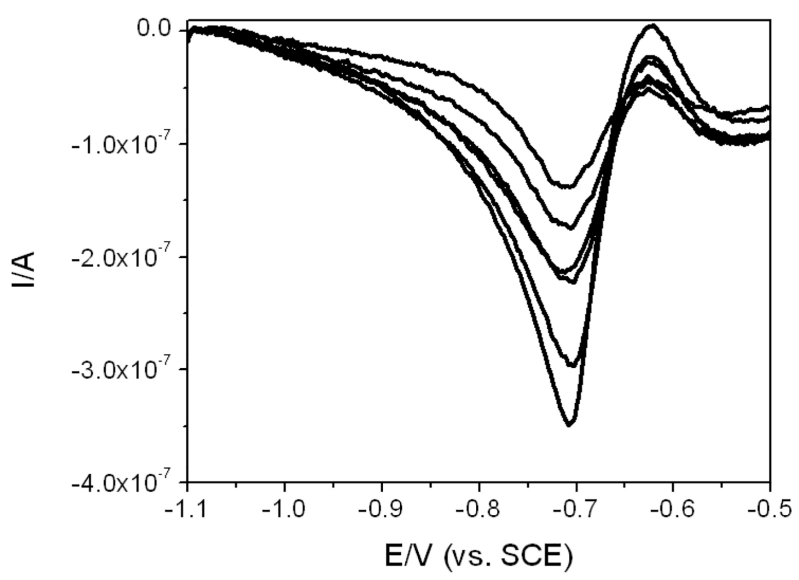

(C)

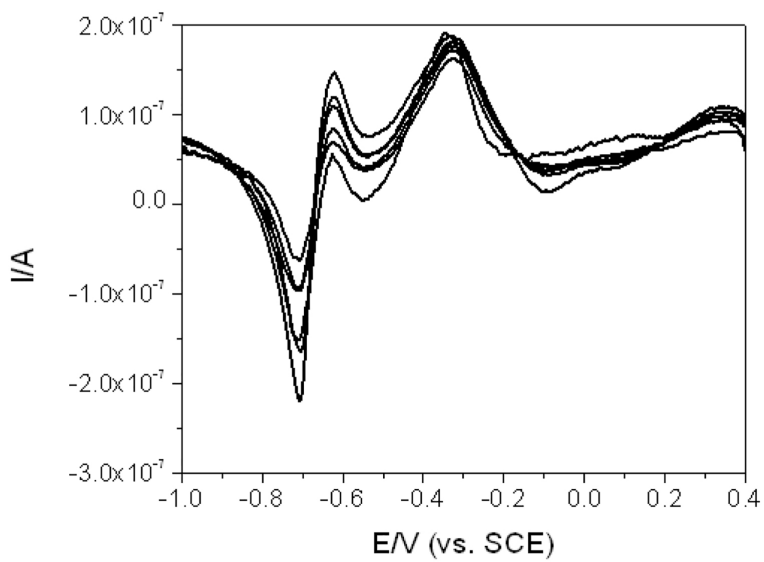

(E)

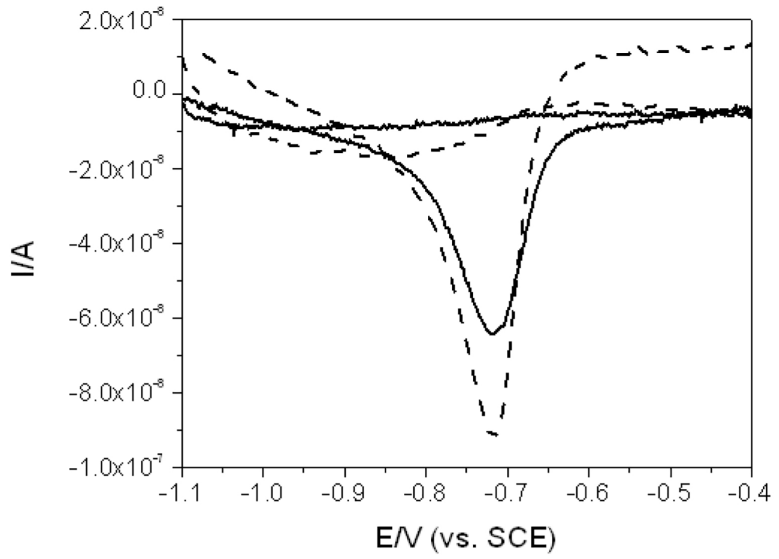

(B)

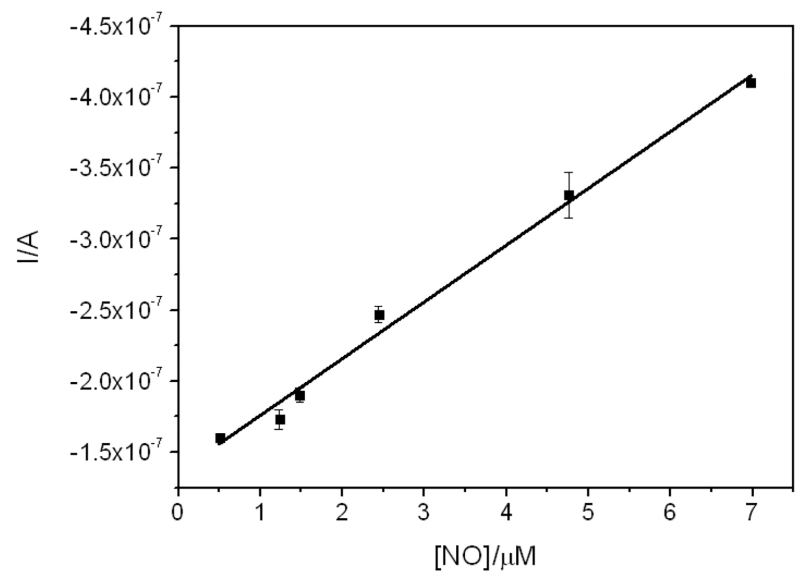

(D)

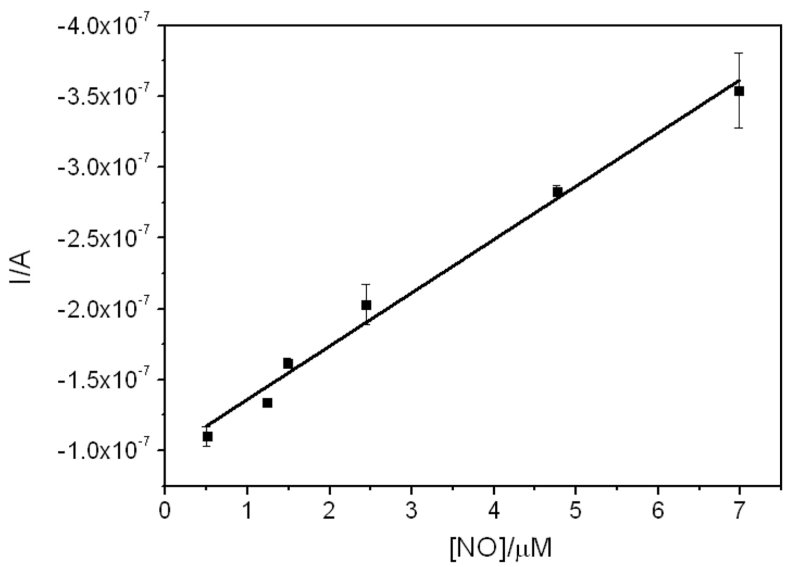

(F) 


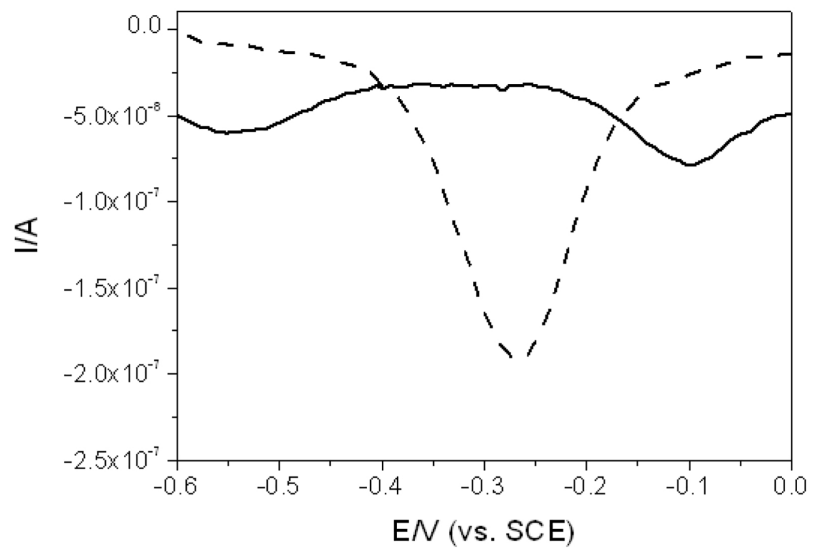

(A)

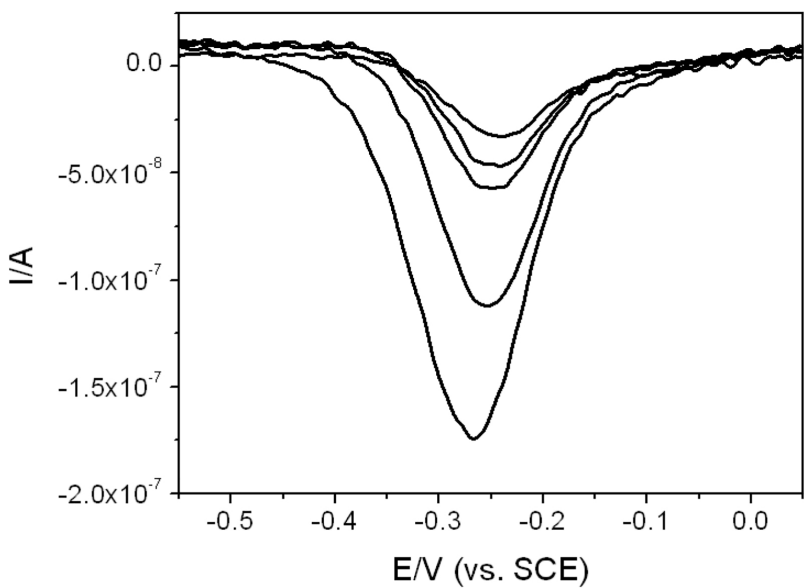

(C)

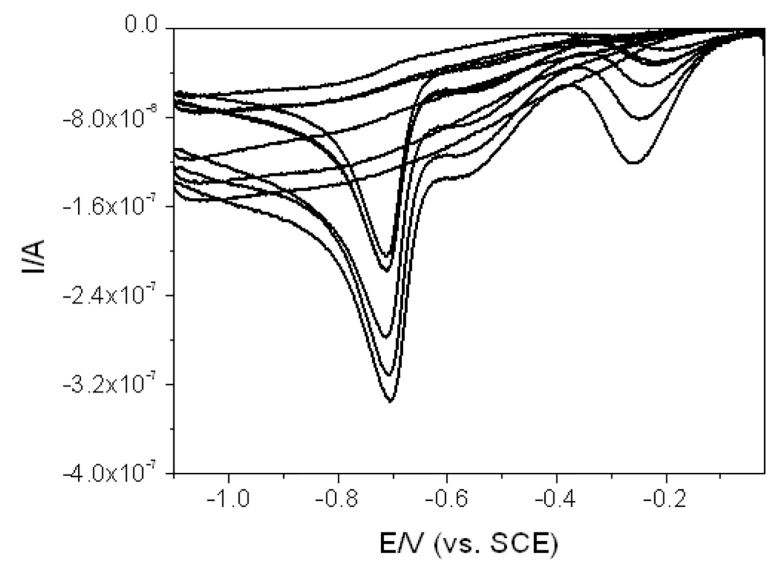

(E)

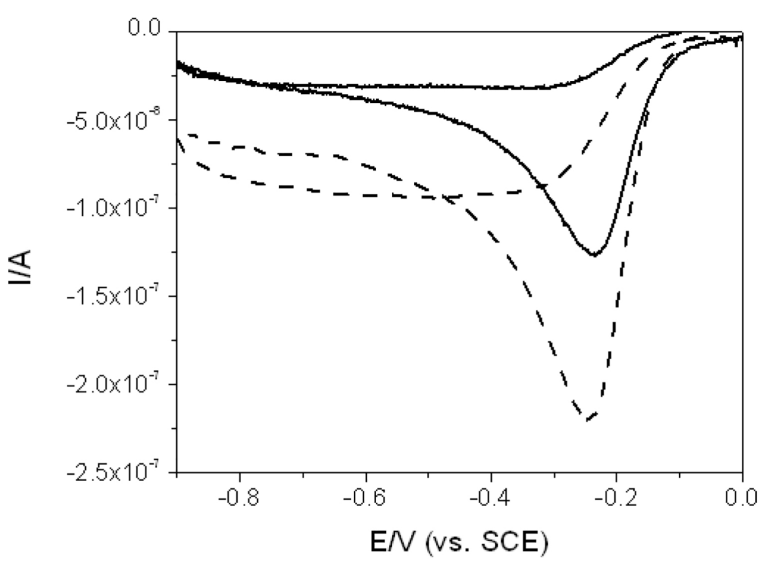

(B)

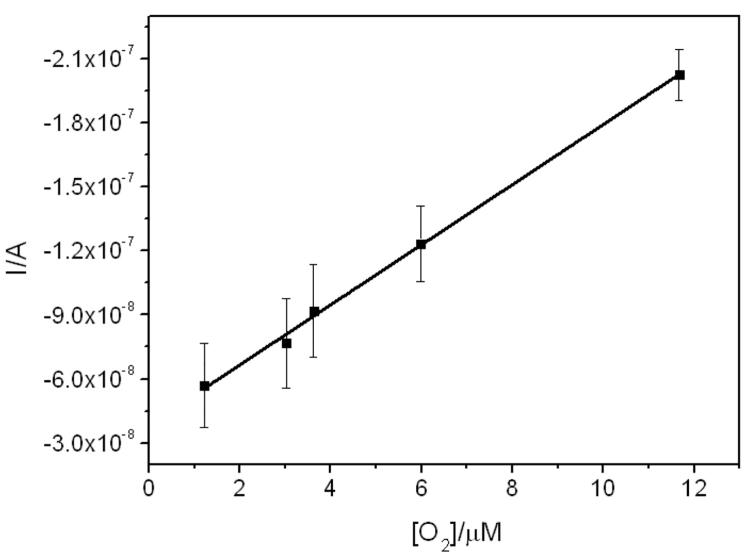

(D)

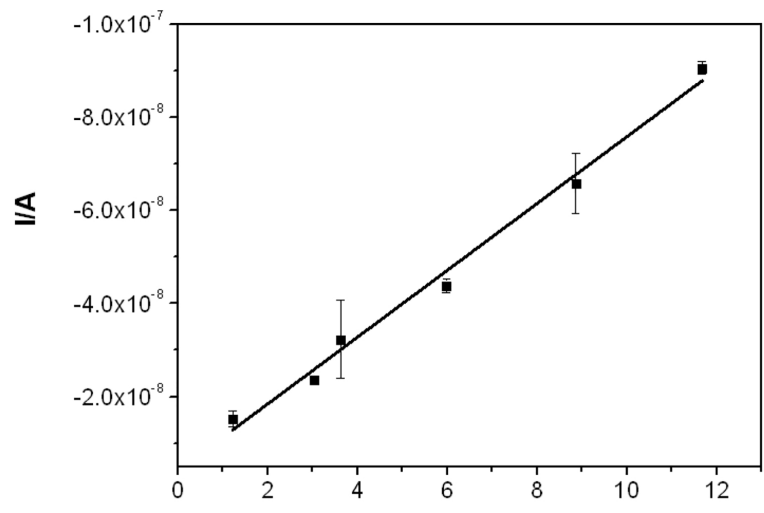

$\left[\mathrm{O}_{2}\right] / \mu \mathrm{M}$ 